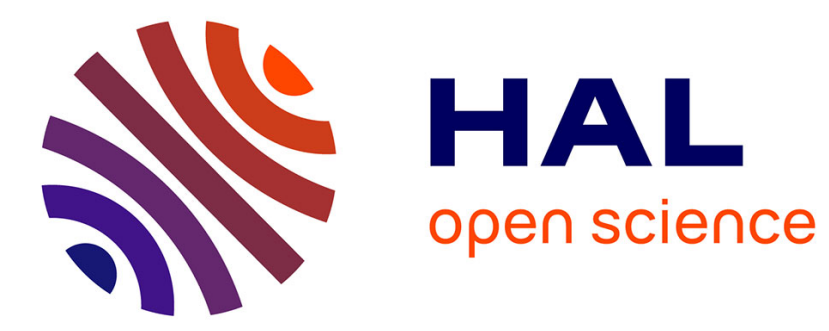

\title{
On the Individual and Social Determinants of Neighborhood Satisfaction and Attachment
}

\author{
Luisa Corrado, Germana Corrado, Emiliano Santoro
}

\section{To cite this version:}

Luisa Corrado, Germana Corrado, Emiliano Santoro. On the Individual and Social Determinants of Neighborhood Satisfaction and Attachment. Regional Studies, 2011, pp.1. 10.1080/00343404.2011.587797 . hal-00719483

\section{HAL Id: hal-00719483 \\ https://hal.science/hal-00719483}

Submitted on 20 Jul 2012

HAL is a multi-disciplinary open access archive for the deposit and dissemination of scientific research documents, whether they are published or not. The documents may come from teaching and research institutions in France or abroad, or from public or private research centers.
L'archive ouverte pluridisciplinaire HAL, est destinée au dépôt et à la diffusion de documents scientifiques de niveau recherche, publiés ou non, émanant des établissements d'enseignement et de recherche français ou étrangers, des laboratoires publics ou privés. 


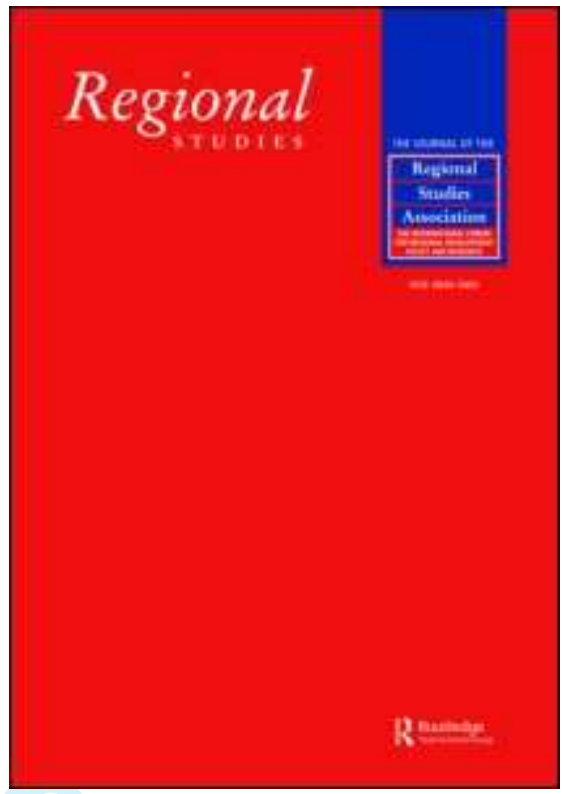

\section{On the Individual and Social Determinants of Neighborhood Satisfaction and Attachment}

\begin{tabular}{|c|l|}
\hline Journal: & Regional Studies \\
\hline Manuscript ID: & CRES-2010-0090.R2 \\
\hline Manuscript Type: & Main Section \\
\hline JEL codes: & $\begin{array}{l}\text { C35 - Discrete Regression and Qualitative Choice Models < C3 - } \\
\text { Econometric Methods: Multiple/Simultaneous Equation Models < C - } \\
\text { Household Behavior and Family Economics < D - Microeconomics, } \\
\text { R1 - General Regional Economics < R - Urban, Rural, and Regional } \\
\text { Economics }\end{array}$ \\
\hline Keywords: & $\begin{array}{l}\text { NeighborhoodSatisfaction and Attachment, Bi-variate Probit, Social } \\
\text { Interactions }\end{array}$ \\
\hline \multicolumn{2}{|c|}{} \\
\hline $\begin{array}{l}\text { Note: The following files were submitted by the author for peer review, but cannot be converted } \\
\text { to PDF. You must view these files (e.g. movies) online. }\end{array}$ \\
\hline CRES_2010_090_CCS_complete.tex
\end{tabular}




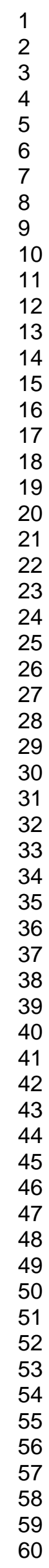

\section{SCHOLARONE ${ }^{m}$ \\ Manuscripts}

7

9

10

11

12

(3)

16

17

18

19

20

22

23

25

26

27

29

30

32

33

34

35

36

39

40

41

42

44

45

46

47

$4 \varepsilon$

49

51

52

53

54

55

57

58

59

60

http://mc.manuscriptcentral.com/cres Email: regional.studies@fm.ru.nl 
On the Individual and Social Determinants of Neighborhood Satisfaction And Attachment

Germana Corrado ${ }^{1}$, Luisa Corrado ${ }^{2}$ and Emiliano Santoro ${ }^{3}$

\begin{abstract}
We explore the determinants of perceived neighborhood quality, emphasizing the nexus between two distinct but correlated dimensions along which individuals evaluate their neighborhoods: satisfaction, traditionally viewed as a cognitive judgement based on the attainment of some standard or aspiration, and attachment, which relates to an affective evaluation. We estimate a bi-variate probit model, using data from the British Household Panel Survey (BHPS). Significant residual correlation is estimated, which suggests that satisfaction and attachment tap both cognitive and affective aspects of individual attitudes. In addition, average satisfaction and attachment at the neighborhood-level emerge as crucial determinants of individual responses.

JEL classification: C35; D10; R23.
\end{abstract}

Keywords: Neighborhood Satisfaction and Attachment, Social Interactions, Bi-variate Probit.

\footnotetext{
${ }^{1}$ University of Rome Tor Vergata. Address: DEI, University of Rome Tor Vergata, 00133 Rome Italy. E-mail: corrado@uniroma2.it.

${ }^{2}$ University of Rome Tor Vergata, Italy and CIMF and CReMic University of Cambridge. Address: Faculty of Economics, University of Rome Tor Vergata, via Columbia 2, 00133 Rome Italy. E-mail: 1c242@cam.ac.uk.

${ }^{3}$ Catholic University of Milan and University of Copenhagen. Address: ITEMQ, Catholic University of Milan, I-20123 Milan, Italy. E-mail: emiliano.santoro@unicatt.it. 


\section{Introduction}

This paper deals with the identification of the individual and social determinants of two dimensions along which individuals are assumed to evaluate the quality of their neighborhood: satisfaction and attachment. ${ }^{1}$ Satisfaction, intended as a cognitive judgement based on the attainment of some standard or aspiration, is often considered as a global indicator of perceived neighborhood quality. By contrast, attachment is viewed as an affective component of individuals' overall response to their neighborhoods. A number of contributions have aimed at understanding to which extent these concepts are usefully distinguishable. In this respect, some intuitive questions have been posed (see, among others, Ringel and FinkELSTEIN, 1991). Can one be satisfied with one's neighborhood, yet unattached to it? Can one be deeply attached to the neighborhood, yet very unsatisfied with it?

The present paper addresses some more subtle questions. To which extent are satisfaction and attachment interrelated and what is their relative contribution to individuals' overall assessment of their neighborhoods? Does the average attitude towards a given neighborhood affect individuals' satisfaction and attachment? ${ }^{2}$ We move away from the fundamental distinction between satisfaction and attachment to assess the extent to which they may overlap, thus tapping both cognition and affect. In doing so, we model the determinants of individual neighborhood satisfaction and attachment in the presence of social interactions, which refer to interdependencies between individual behavior/characteristics and the behavior/characteristics of others within a common group, the neighborhood. These interactions generally arise in the form of: (i) contextual effects based on the quality and other environmental characteristics of the neighborhood; (ii) endogenous effects induced by neighbors' behavior; (iii) exogenous effects that depend on the socio-demographic characteristics of the peer-group.

The importance of decomposing agents' interactions within the neighborhood into exogenous and endogenous factors has been widely recognized in the literature on social interactions and social capital (see IoAnnides and ZABEL, 2003; Durlauf and FAFChamps, 2005; Brock and Durlauf, 2006). With reference to neighborhood effects, social capital characterizes the way individual behavior is influenced by the behavior and characteristics of those who share a common resource or social space. Having friends or family members in one's 
neighborhood (i.e. social networks), especially those who are geographically close and willing to help, is an example of social capital (O'Brien et al., 2005; WESTERn et al., 2005). ${ }^{3}$ For instance, KAN (2007) shows that the availability of emergency assistance to a household from someone living nearby does deter the household from moving. In the present paper we study how inter-personal effects shape the accumulation of social capital ${ }^{4}$ and affect individuals' evaluation of their neighborhoods over a cognitive and an affective dimension.

Data from the British Household Panel Survey (BHPS hereafter) are explored over the period 1996-2005 within a pooled bi-variate probit framework. Such modeling choice allows us to account for the presence of inter-dependent responses and potential unobservable effects. In fact, we assume that interactions between individuals and their reference group are only partly due to observable effects, as both satisfaction and attachment can reflect the impact of other unobservable cognitive and affective factors influencing individual responses.

The econometric analysis produces three novel results. First, we provide empirical support to our conjecture, as satisfaction and attachment display substantial correlation that cannot be entirely accounted for by the inclusion of endogenous, exogenous and contextual effects. This signals that both constructs can be seen as tapping cognitive and affective aspects of (perceived) neighborhood quality.

Second, individual responses are strongly influenced by both endogenous effects, which are captured by including average satisfaction and attachment in the set of covariates, as well as by the network of informal social ties shared by members of the same neighborhood. A main finding is that the joint probability of being satisfied with and attached to the neighborhood increases substantially following a marginal increase in the average number of neighbors that display attachment, whereas a marginal increase in the average degree of satisfaction only exerts a negligible effect.

Third, other factors acting at the peer-group level are found to play an important role. Individual responses to contextual factors suggest that externalities such as crime or vandalism, pollution and noise exert a negative impact on both responses. In this respect, it is expected that policies aimed at removing such externalities are likely to produce substantial social benefits.

Overall, our results shed light on important determinants of cognitive and affective re- 


\section{Framing the Problem}

The literature on neighborhood quality has traditionally examined survey data on neighborhood satisfaction in connection with other indicators of neighborhood attachment. Neighborhood satisfaction has classically been related to residents' evaluations about a number of contextual and social features of their environments. However, as recognized by SHUMAKER and TAYLOR (1983), satisfaction is often viewed as a criterion measure in and of itself. As such, satisfaction tells little about the behavioral significance of differing evaluations of a given neighborhood. To address this issue, the literature on neighborhood quality has complemented measures of satisfaction with measures of attachment, so as to account for behavioral implications along with objective responses (see, e.g., Connerly and MARAns, 1985). In this respect, SHumaker and TAYlor (1983) describe attachment as a "positive affective bond or association between individuals and their environment" (p. 233).

In summary, the dichotomy between attachment and satisfaction reflects the direction that the literature on subjective well-being has recently taken (KAHNEMAN and DEATON, 2010), that is to distinguish between affective measures, often expressed in terms of emotions 
such as happiness or pleasure, and cognitive measures, such as satisfaction, which implies an evaluation based on the attainment of some standard or aspiration. In this respect, it is expected that attachment to the neighborhood is more closely related to the affective component of perceived neighborhood quality, whereas the revealed degree of satisfaction with the neighborhood reflects a cognitive evaluation. Therefore, it should in principle be possible to distinguish between satisfaction and attachment on the basis of this classification. However, things are not that straightforward in practice. In fact, some overlap between satisfaction and attachment may emerge, as both concepts are likely to tap cognition and affect (see, e.g., Hunter, 1974; Fishbein and Ajzen, 1975; Kaplan and Kaplan, 1982). For instance, emotional involvement with the neighborhood may produce a sense of attachment that transcends any objective evaluation about the neighborhood. Also, one can feel satisfied with her neighborhood but fundamentally unattached to it if she has not developed any social or emotional ties to the place (CONNERLY and MARANS, 1985).

We address these issues within a unified framework that emphasizes individuals' perception of their neighborhood quality as the outcome of two (potentially) correlated factors: (i) the degree of satisfaction with the neighborhood, which relates to the cognitive component of individual responses; (ii) individuals' attachment to the neighborhood, which pertains to the affective component.

Following the literature on social interactions, we account for a number of determinants of satisfaction and attachment acting at the individual and peer-group (neighborhood) level. At the neighborhood level, we include contextual effects and social capital indicators. Contextual effects reflect the influence exerted by factors shared by the members of the group which are predetermined with respect to the realization of the phenomena under scrutiny (e.g., environmental characteristics such as pollution, noise, etc.). With reference to neighborhood effects, social capital characterizes the way individual behavior is influenced by the behavior and characteristics of those sharing the same environment. ${ }^{5}$ DuRLAUf and FAFCHAMPS (2005) provide a broad overview of the empirical literature on social capital. In our setting, social capital indicators are further classified into: (i) endogenous effects induced by neighbors' attitudes/behavior (i.e., neighbors' satisfaction and attachment); (ii) inter-personal and social group effects, which capture the density of inter-personal linkages and social ties developed 
within the neighborhood (e.g., availability of somebody providing assistance in a crisis, length of residence, housing tenure etc.); (iii) other effects that depend on the socio-demographic characteristics of the peer group (e.g., average marital status, educational attainment, income etc.). ${ }^{6}$ In the remainder of this section we explore a conceptual framework which is particularly suitable to frame our problem.

A popular approach to study social interactions consists of augmenting regressions that include individual-level covariates with measures of group-level characteristics (see SoLON et al., 2000; Ginther et al., 2000; Brock and Durlauf, 2001). In most of these works significant coefficients on group-level variables are interpreted as indicating the presence of peer-group effects. The identifying assumptions underlying much of the research in this area were first formally analyzed by MANSKi $(1993,1995)$ within the popular linear-in-means framework. ${ }^{7}$ We adapt this conceptual benchmark to account for the joint effect of individual and social (neighborhood) effects on individuals' satisfaction with the neighborhood and attachment.

We start by assuming that $z_{k i g}^{*}$ denotes the $k^{t h}$ response $(k=1,2, . ., K)$ of the $i^{\text {th }}$ individual in the $g^{\text {th }}$ neighborhood. In our case $K=2$, as individuals are assumed to jointly express their satisfaction with the neighborhood $(k=1)$ and attachment $(k=2)$. The following linearin-means model can be assumed to generate the latent process for each of the two responses under scrutiny:

$$
z_{k i g}^{*}=\gamma_{k}^{\alpha} \alpha_{g}+\gamma_{k}^{\epsilon} \epsilon_{i g}+\gamma_{k}^{w} w_{i g}+\delta_{k} s_{g}+u_{k i g}, \quad k=1,2
$$

where $\alpha_{g}$ denotes contextual factors in the environment shared by the members of the group, $\epsilon_{i g}$ is a vector of variables capturing individuals' social status and inter-personal characteristics, $w_{i g}$ is a vector of socio-demographic control variables, $s_{g}$ equals the group's stock of social capital and $u_{k i g}$ captures random and unobservable (to the modeler) characteristics associated with individual $i$. Coefficient $\delta_{k}$ is of particular interest, as it indexes the effect of the stock of social capital on individual choices. A positive (negative) slope coefficient implies that marginal utility deriving from individual choices/preferences increases (decreases) in the peergroup status quo, thus reflecting strategic complementarity (substitutability).

Following Manski (1993), Becker and Murphy (2000) and Durlauf and Fafchamps (2005), we assume that the stock of social capital depends on the subjective expectation of the 
average choice in the group, $E_{i} z_{k g}^{*}, k=1,2$, as well as on group-level average inter-personal and social characteristics $\left(\epsilon_{g}\right)$ and demographic background $\left(w_{g}\right)$ :

$$
s_{g}=f\left(E_{i} z_{k g}^{*}, \epsilon_{g}, w_{g}\right), k=1,2 .
$$

In the remainder we assume that beliefs are consistent with the structure of choices/behavior in the model. This amounts to imposing $E_{i} z_{k g}^{*}=z_{k g}^{*}$. This property, known as self-consistency, means that the subjective expectation of the average choice in one's group corresponds to the mathematical conditional expectation of the average choice, given the information set of each agent. ${ }^{8}$ On empirical grounds, this assumption can be justified based on the fact that the average number of individuals in the peer-group (or neighborhood) is large enough to assume that individual responses have negligible impact on the average response in the same neighborhood.

\section{Data Description}

We use data from the BHPS over the period 1996-2005. The BHPS is a multi-purpose study with three main peculiarities: (i) it follows the same representative sample of individuals over time; (ii) it is household-based, as every adult member of the sampled households is interviewed $;^{9}$ (iii) it contains sufficient cases for a meaningful analysis of certain groups, such as the elderly or lone parent families. The BHPS is designed as an annual survey of each adult member of a nationally representative sample that was originally composed by 5,500 households. Additional samples in Scotland, Wales and Northern Ireland have been made available recently. The same individuals are re-interviewed in successive waves and, if they split-off from original households, all adult members of their new households are also interviewed. In contrast with most cohort studies, the sample covers the whole population, and not simply narrowly defined age ranges. ${ }^{10}$

When dealing with neighborhood effects, the definition of the reference group is of crucial importance for a correct measurement of social and economic inter-dependencies. To evaluate how social interactions affect British households' neighborhood satisfaction and attachment, we identify their reference-group through the area-code, the Primary Sampling Unit (PSU). 
In the BHPS the population of postcode sectors is ordered into 18 regions. At the first stage of sampling, 250 postcode sectors are selected as PSUs. ${ }^{11}$ All PSUs are then checked for size to ensure that they contain, at minimum, 500 households.

[Table 1 about here]

[Table 2 about here]

In Table 1 we list the variables used in our econometric analysis, while Table 2 reports the main summary statistics. As to the dependent variables, individual neighborhood satisfaction and attachment to the neighborhood are proxied by the (binary) responses to the following questions, respectively: (i) "Overall, do you like living in this neighborhood?"; (ii) "If you could choose, would you stay here in your present home or would you prefer to move somewhere else?". ${ }^{12}$ In light of the discrete nature of the responses to (i) and (ii), the associated variables will be respectively denoted by $z_{1 i g}$ and $z_{2 i g}$, so as to distinguish them from their continuous counterparts introduced in the linear-in-means framework (1)-(2). In the next section we formalize an appropriate econometric framework to account for individuals' joint response on neighborhood satisfaction and attachment.

As to the explanatory variables, we include both 'Socio-Demographic Controls' $\left(w_{i g}\right)$ and 'Inter-personal and Social Effects' $\left(\epsilon_{i g}\right)$ at the individual level. The first category comprises characteristics such as age, gender, educational attainment, real personal income, number of children in the household and marital status. ${ }^{13}$ The second class of regressors comprises variables capturing (i) social support/help (from family, friends and neighbors) in case of need/emergency, (ii) religious participation, (iii) length of residence, (iv) type of home tenure. ${ }^{14}$

At the neighborhood level, we include 'Contextual Effects' $\left(\alpha_{g}\right)$ and 'Social Capital Indicators' $\left(s_{g}\right)$. As mentioned above, contextual effects are intended as factors shared by the members of the group which are predetermined with respect to the realization of the phenomena under scrutiny (see GRAHAM, 2008). In our specific case these may comprise 
characteristics of the place where people live, which pertain to the quality of the surrounding environment (i.e., neighbors' and street noise, lack of light, pollution and other environmental problems, crime and vandalism).${ }^{15}$ Social capital indicators have been classified into three categories: (i) 'Endogenous Group Effects', (ii) 'Inter-personal and Social Group Effects', and (iii) 'Socio-Demographic Group Controls'. The first category comprises the average (self-reported) preference for the neighborhood $\left(z_{1 g}\right)$ and the propensity to stay in the current place of residence $\left(z_{2 g}\right)$. Inter-personal and social group effects and socio-demographic group controls at the neighborhood level are denoted by $\epsilon_{g}$ and $w_{g}$, respectively. When averaged at the neighborhood level, personal and inter-personal characteristics may be seen as contributing to the formation of social capital. As such, they proxy the density of inter-personal linkages and social ties developed within the neighborhood.

[Table 3 about here]

As a preliminary inspection, it is useful to check whether the correlation between individual responses on neighborhood satisfaction $\left(z_{1 i g}\right)$ and preference to stay $\left(z_{2 i g}\right)$ display any correlation. Table 3 reports the Pearson correlation coefficients between the two dependent variables, as well as between each of them and other covariates employed in the study. ${ }^{16}$ As expected on a priori grounds, satisfaction and attachment (or preference to stay in the neighborhood) are positively correlated (0.30), thus indicating that although they display positive co-movement, each has significant variation not explained by the other. ${ }^{17}$ The remainder of the paper is explicitly aimed at uncovering these aspects.

\section{The Econometric Framework}

The econometric implementation of the behavioral paradigm introduced in Section 2 poses a number of challenges. In particular, two factors need to be addressed. First, as specified in Section 3, $z_{1 i g}^{*}$ (satisfaction with the neighborhood) and $z_{2 i g}^{*}$ (attachment) are going to be captured through the (binary) responses to the following questions, respectively: (i) "Overall, do you like living in this neighborhood?" (where $z_{1 i g}=1$ if the answer is "yes" and 0 otherwise); 
(ii) "If you could choose, would you stay here in your present home or would you prefer to move somewhere else?" (where $z_{2 i g}=1$ if the answer is "yes" and 0 otherwise). Second, the problem we have posed emphasizes the potential inter-connection between individuals' neighborhood satisfaction and attachment.

To account for the first problem, we resort to a suitable econometric framework. In this respect, we observe that discrete choice models are traditionally based on the assumption of utility maximizing behavior, whereby individuals choose among a certain number of alternatives that lead to different levels of utility (GREene, 2003). Our modelling strategy reflects this fundamental mechanism and can be regarded as a convenient way to bridge the empirical analysis with the study of social interactions and neighborhood effects. ${ }^{18}$ As to the second point, we extend the univariate binary choice model, so as to allow agents to make multiple choices. A natural extension commonly used in applied research is the bi-variate probit model with (possibly) correlated disturbances. Beyond the estimation of each of the binary choice equations (jointly or separately), applied researchers are generally interested in the dependence structure of the two binary-choice decision equations. In the context of the bi-variate probit model, the correlation coefficient between the error disturbances in the latent regression equations provides us with a simple summary measure of how the unobservables interact with each other in the underlying equations (CHEN and ZHOU, 2007).

We can define satisfaction with a specific neighborhood $g$ and attachment to the same neighborhood as the joint model of two binary outcomes: ${ }^{19}$

$$
z_{1 i g}=\left\{\begin{array}{c}
1 \text { if } z_{1 i g}^{*}>0 \\
0 \text { if } z_{1 i g}^{*} \leq 0
\end{array}\right\} \quad z_{2 i g}=\left\{\begin{array}{ccc}
1 \text { if } z_{2 i g}^{*}>0 \\
0 \text { if } z_{2 i g}^{*} \leq 0
\end{array}\right\},
$$

where we implicitly assume repeated measurements $(t=1, \ldots, T)$.

Choices with respect to $z_{k i g}(k=1,2)$ are coded to lie in the set $\{1,0\}$ and the underlying latent process is isomorphic to the linear-in-means model (1)-(2):

$$
\begin{aligned}
z_{k i g}^{*} & =\mathbf{x}_{k i g} \boldsymbol{\beta}_{k}+u_{k i g}, \\
\mathbf{x}_{k i g} & =\left[z_{k g}, \alpha_{g}, w_{g}, \epsilon_{g}, w_{i g}, \epsilon_{i g}\right]
\end{aligned}
$$

Furthermore, the error terms can be thought as comprising a common element, $v_{i g}$, to both equations and a term, $\varepsilon_{k i g}$, specific to each of them: 


$$
\begin{aligned}
& u_{1 i g}=v_{i g}+\varepsilon_{1 i g} \\
& u_{2 i g}=v_{i g}+\varepsilon_{2 i g}
\end{aligned}
$$

where $v_{i g} \sim N(0,1), \varepsilon_{k i g} \sim N(0,1)$. Therefore, we allow for the presence of correlated effects:

$$
\rho=\operatorname{Cov}\left[u_{1 i g}, u_{2 i g} \mid \mathbf{x}_{1 i g}, \mathbf{x}_{2 i g}\right]
$$

As the error terms share a common element, the joint probability $P\left(z_{1 i g}=1, z_{2 i g}=1\right)$ is defined by a bi-variate normal distribution:

$$
P\left(z_{1 i g}<\mathbf{x}_{1 i g} \boldsymbol{\beta}_{1}, z_{2 i g}<\mathbf{x}_{2 i g} \boldsymbol{\beta}_{2}\right)=\int_{-\infty}^{u_{1 i g} u_{2 i g}} \int_{-\infty}^{\phi} \phi\left(\mathbf{x}_{1 i g} \boldsymbol{\beta}_{1}, \mathbf{x}_{2 i g} \boldsymbol{\beta}_{2}, \rho\right) d u_{1 i g} d u_{2 i g}=\Phi\left(\mathbf{x}_{1 i g} \boldsymbol{\beta}_{1}, \mathbf{x}_{2 i g} \boldsymbol{\beta}_{2}, \rho\right),
$$

where $\phi(\cdot)$ and $\Phi(\cdot)$ denote the standardized bi-variate normal density and the associated distribution function, respectively.

A further step in the specification of the model consists of accounting for the potential endogeneity between our set of regressors and the individual error terms. If we assume that unobserved individual-specific effects are in place, and denote them with $e_{k i g}(k=1,2)$, the specification of the bi-variate latent model is: ${ }^{20}$

$$
\begin{aligned}
z_{k i g, t}^{*} & =e_{k i g}+\mathbf{x}_{k i g, t} \boldsymbol{\beta}_{k}+u_{k i g, t}, \quad k=1,2 \quad t=1, \ldots, T \\
\rho^{\prime} & =\operatorname{Cov}\left[u_{1 i g, t}, u_{2 i g, t} \mid \mathbf{x}_{1 i g, t}, \mathbf{x}_{2 i g, t}, e_{1 i g}, e_{2 i g}\right]
\end{aligned}
$$

In linear models $e_{k i g}$ could be eliminated through first difference estimation or via a withintransformation. The non-linear form we consider does not allow us to take this route. Pursuing a dummy variable approach is not advisable either, for two main reasons: (i) the potential loss of too many degrees of freedom, and (ii) the incidental parameters problem, which would lead to inconsistent estimates. In the attempt to control for the correlation between $\mathbf{x}_{k i g, t}$ and $e_{k i g}$, we follow MundLAK (1978), who proposes a modified random effects model where unobservable effects are assumed to be normally distributed, conditional on the covariates. This translates into a "within" estimator in the random effects framework. When the error 
distribution is symmetric, the GLS estimator resulting from such a specification is identical to the fixed effect estimator of the basic model. As discussed by Hsiao (2003), this is an unbiased estimator. WOOLDRIDGE (2002) stresses that the inclusion of time averages of the covariates allows for a consistent estimation of all parameters in the pooled probit analysis. Thus, we extend this approach to our bi-variate model, assuming:

$$
\begin{aligned}
u_{k i g, t} \mid \mathbf{x}_{k i g, t} & \backsim N\left(0, \sigma_{k u}^{2}\right), \\
e_{k i g} \mid \mathbf{x}_{k i g, t} & \backsim N\left(\overline{\mathbf{x}}_{k i g} \gamma_{k}, \sigma_{k e}^{2}\right), \\
\overline{\mathbf{x}}_{k i g} & =T^{-1} \sum_{t=1}^{T} \mathbf{x}_{k i g, t}, \quad k=1,2 .
\end{aligned}
$$

Finally, a word of caution is in order about the importance of estimating cluster-robust standard errors in a pooled regression. We control for the correlation of responses given by the same individual over time by clustering repeated observations with respect to the panel personal identification number. This allows us to account for cases in which the assumption of independently and identically (normally) distributed errors is violated.

\section{Estimation Results}

Table 4 reports the results from the estimation of the bi-variate probit model with correlated error terms and the two distinct univariate probit models for the individual responses to satisfaction and attachment. The marginal effects associated with the explanatory variables for the entire probability space are reported in Table 5: the last two columns of the table also report the marginal effects of the model with no unobservable correlated components in the error term.

[Table 4 about here]

[Table 5 about here]

The $\chi^{2}(1)$ Wald test on the statistical significance of the correlated effects $\left(H_{0}: \rho=0\right.$ vs $\left.H_{1}: \rho \neq 0\right)$ suggests not to accept the null hypothesis of no correlation between the error 
terms in the latent regression equations (4). This is also the case when accounting for the presence of unobservable effects at the individual level: the estimation results and marginal effects for this case are reported in Tables 6 and 7 , respectively.

[Table 6 about here]

[Table 7 about here]

This evidence indicates that satisfaction and attachment display some correlation that cannot be entirely accounted for by the inclusion of endogenous, exogenous and contextual effects. Consequently, both neighborhood satisfaction and attachment are seen as tapping both cognitive and affective aspects of individuals' responses to their neighborhoods, as initially conjectured. From a purely statistical viewpoint, a positive and statistically significant $\hat{\rho}$ indicates a positive and interactive correlation between the two dependent variables, suggesting that it is potentially harmful to explore them in a separate fashion. An alternative way to interpret a statistically significant correlation between the error terms is to think about the impact of other determinants of neighborhood satisfaction and attachment that may not be taken to the model, although they affect the dependent variables. Therefore, ruling out the assumption of correlated disturbances may potentially bias our estimates.

\subsection{Endogenous and Contextual Effects}

The econometric analysis shows that endogenous group effects proxied by the average degrees of neighborhood satisfaction and attachment are crucial determinants of individual preferences. The average degree of satisfaction with the neighborhood exerts a positive effect on the probability that the $i^{\text {th }}$ individual in the $g^{\text {th }}$ neighborhood is satisfied. This is in line with recent works on neighborhood conditions that emphasize the role played by neighborhoods in shaping individual and social outcomes. ${ }^{21}$ Analogously, attachment at the individual level is positively affected by its average counterpart at the neighborhood level. As a matter of fact, lower residential turnover (which should reflect higher attachment) increases social integration, as well as the likelihood that neighbors know each other, watch out for each other, 
share social values and norms, thus enabling them to exert informal social control. By contrast, lower attachment to the neighborhood restricts the ability of individuals to develop informal ties and friendship networks with other residents (see ElLIOTT et al., 1996). Lower attachment increases the likelihood that neighbors are strangers, reducing their ability to form and maintain informal social relationships, and impairing their ability to work collectively to enforce local social control, ultimately lead to the breakdown of informal social ties.

We also find that the impact of the average degree of attachment exerts a positive effect on neighborhood satisfaction. This evidence is confirmed by the associated marginal effect: the joint probability of responding "Yes, I like my neighborhood and I prefer to stay" increases substantially $(93.8 \%)$ following a marginal increase in the average number of neighbors that prefer to stay (see Table 5), thus indicating that variations in the average degree of attachment act as a potent multiplier of both individual satisfaction and attachment. As to the effect of group-level average satisfaction with the neighborhood, its marginal effect is negative, but not statistically significant when fixed effects à la MundLAK (1978) are not accounted for. Otherwise, when these are modeled (see Table 7), the effect is still negative but statistically significant $(-14,8 \%)$. Thus, it is likely that unobservable effects are particularly relevant in determining the impact of the average degree of satisfaction on the joint probability to be satisfied with and attached to the neighborhood. Endogeneity may in fact arise as a consequence of computing neighborhood satisfaction at the peer-group level as the cross-sectional average of individual satisfaction, while omitting to account for a time-invariant component at the individual level that potentially affects the average measure. ${ }^{22}$ From a conceptual viewpoint we could interpret a negative relationship as indicating that there is substantial divergence between the individual and peer-group assessment on the two domains (attachment and satisfaction) on which respondents express their attitudes towards the neighborhood. This somewhat counter-intuitive evidence might signal that the affective evaluation of one's neighborhood acts as a stronger determinant of individuals' attitudes, compared to the cognitive assessment at the group level, so that preferences expressed by peers on these grounds are less likely to be driving the average individual's affective evaluation.

As expected on a priori grounds, the impact of the contextual effects suggests that externalities such as crime or vandalism, pollution, and noise have a negative impact on both 
dependent variables. This is in line with recent empirical evidence showing that unfavorable neighborhood characteristics and environmental problems negatively affect housing satisfaction and residential mobility (e.g., Diaz-Serrano, 2006). Compared to previous studies, our evidence suggests that there are objective elements that affect individual responses to neighborhood satisfaction and attachment, even after controlling for endogenous factors that exert a predominant impact on individual attitudes. Most importantly, it appears that policies aimed at removing unfavorable contextual aspects are likely to substantially improve not only individuals' neighborhood satisfaction, but also their sense of attachment, ultimately improving individuals' overall responses to their neighborhoods.

\subsection{Socio-Demographic Controls at the Individual and Group Level}

Overall, the impact of socio-demographic factors is statistically significant only at the individual level, whereas neighbors' average socio-demographic background does not generally contribute to the formation of social capital and, in turn, to attachment and satisfaction with the neighborhood. The only exception is represented by the real personal income at the neighborhood level, which exerts a positive impact on the probability of being satisfied with the neighborhood, while having no effect on neighborhood attachment. Intuitively, the higher average income, the higher the probability that members of the neighborhood enjoy living in a wealthy area. This view is supported by recent evidence on the impact of income on measures of satisfaction and emotional well-being (KAHNEMAn and DEATON, 2010), which shows that income is more closely related to measures of overall satisfaction. In addition, there is widespread evidence showing that residents of wealthy areas generally report their neighborhood to be healthier, with higher sense of community, higher quality of life and lower crime rates than low-income neighborhoods (PICKETt and PEARL, 2001; Brisson and Usher, 2005; Ortalo-Magne and Rady, 2008). We also find that a marginal increase in the proportion of younger adults in the neighborhood aged 25-34 and 35-44 has a positive effect on the probability that an individual is both attached to and satisfied with the neighborhood. Typically, this is the age range in the life cycle during which many adults seek out a place to settle down and start a family. Indeed, families with young children are more likely to relate with

the neighborhood in many different ways. For example, children play and socialize with the 
neighbors and usually attend school in the neighborhood. The presence of children may also reinforce local organizational and social ties as sources of support. This centrality of place in the socialization process increases the importance that families with young children play in the community, thus nurturing individual attachment (MESCH and MANOR, 1998).

Previous studies have identified the importance of personal and household characteristics for residential mobility (SPEARE et al., 1982; VARADY, 1983). In particular, age, marital status, educational attainment and job type are found to have significant effects on the preference to stay. It is not surprising that younger people are more likely to move, so as to pursue new economic or educational opportunities (LiCHTER et al., 1995). The impact of age on attachment offers an interesting picture. Being in the 25-34 age interval reduces by about $4 \%$ (with respect to respondents in the reference age interval) the joint probability of being attached and satisfied with the neighborhood. Both the bi-variate and the univariate probit models highlight a negative effect on attachment. This is also the case when individual unobservable effects à la MundLAK (1978) are accounted for (see Table 7). Having most of their life ahead, respondents in this age class are likely to have the ambition to improve their social position, experience new places and move elsewhere. Tables 5 and 7 also suggest that elderly people are associated with higher probabilities to be attached and satisfied with the neighborhood. This can result from the fact that elderly respondents tend to attach a higher weight to personal and social stability, compared to their younger counterparts. The expected marginal effect estimated for the category "Age over 65" is rather strong, implying a positive change in the joint probability of responding "Yes, I like my neighborhood and I prefer to stay", which ranges from $12.8 \%$ to $13.6 \%$, depending on whether quasi-fixed effects are considered or not. This effect is expected on a priori grounds, as habits, unwillingness to be subject to the hurly-burly of moving out, together with the difficulty to get in touch with friends among the neighbors renders moving out of the neighborhood a harder decision for old people. Moreover, the sense of community in the elderly population is likely to acquire higher importance compared to people in other age intervals. Overall, we confirm previous evidence showing how different stages in the life cycle are important in influencing the propensity to move (see HARBISON, 1981; LEE et al., 1994).

As to the role of the marital status, being married is associated with a higher probability 
of being attached to the current place of residence, while exerting no statistically significant effects on the probability of being satisfied with the neighborhood. This could indicate that married respondents prefer a pleasant and safe environment where they can build a stable relationship with their family. Conversely, being separated or divorced increases individuals' preference to change neighborhood, which signals the propensity of these respondents to change their life and build up a new perspective, establishing new social relationships. As a matter of fact, the positive trend in the number of separation/divorce events represents one of the main causes of a wider variation in life courses. Recent research shows the occurrence of a separation or divorce appears as one of the main determinants of residential mobility (Fischer and Malmberg, 2001). A possible explanation comes from the fact that separated and divorced respondents tend to opt for smaller or otherwise less attractive housing, often due to the emergence of financial constraints (induced, for example, by a drop in the household disposable income, the occurrence of legal costs, etc.).

Also respondents characterized by graduate or professional training beyond the college are less likely to be attached to their neighborhood than those with lower education. This is generally the case as more educated people are meant to be culturally open-minded and incline to experience different environments. These are generally keen to change neighborhood, even after controlling for individual income.

\subsection{Inter-personal and Social Effects at the Individual and Group Level}

Among the set of variables capturing inter-personal effects at the neighborhood level, the average availability of someone providing assistance in the event of a crisis/emergency exerts a positive effect on individual attachment to the neighborhood, while having no statistically meaningful effect on individual neighborhood satisfaction, as reported in Table 5. In general, a marginal increase in the average availability of assistance exerts the following effects: (i) it increases the joint probability of being satisfied with and attached to the neighborhood; (ii) it reduces the joint probability of being satisfied and unattached; (iii) it increases the marginal probability of being attached. Table 7 reports the results for the case with individual latent 
traits that may affect the propensity to receive help: we find that a $1 \%$ increase in the average availability of support in the neighborhood lowers the joint probability of being satisfied with the neighborhood but unattached to it by $19.1 \%$, while increasing the marginal probability of being attached by $17.4 \%$. Overall, these results suggest that the average availability of help in a crisis might represent an affective support of last resort that makes more convenient but not necessarily more pleasant to remain in the neighborhood. Moreover, the effect of the average availability of help in a crisis is stronger than that exerted by the same covariate at the individual level, which signals that neighborhood satisfaction and attachment are predominantly affected by the presence of a broad network of social ties at the neighborhood level. This evidence complements the findings of KAN (2007), who shows that the availability of emergency assistance to a household from someone living nearby does deter the household from moving, with a stronger negative effect on long-distance mobility than short-distance mobility. Our results carry important additional information compared to the evidence of this paper, as we are able to disentangle the individual from the social impact of help availability or assistance.

To account for the effect exerted by the tenancy status at the individual level, we control for respondents who rent an accommodation in a given neighborhood, as compared to homeowners. Furthermore, we distinguish between public and private housing renters. Table 5 shows that the expected marginal effect on the joint probability of being satisfied with and attached to the neighborhood is negative in the case of both private and public housing renters, although marginally stronger in the former case (-7\% vs $-5.6 \%)$. Concurrently, the marginal probability of being attached to the neighborhood is expected to decrease by $7.2 \%$ for private renters and by $4.5 \%$ for public renters. When accounting for individual unobservable effects the results are rather similar, although the magnitude of the coefficients is now filtering out individual latent traits, as observed at different stages of the analysis. Overall, the reason why renters (public and private) are tendentially more mobile than homeowners and less attached to their neighborhood may be that homeownership creates incentives to improve the quality of the neighborhood, which is typically capitalized into housing values. Therefore, homeowners might be expected to be more active then renters in maintaining or improving neighborhood conditions because they will benefit both economically and socially from these activities.

When considering the effect exerted by the average share of renters in the neighborhood, 
the results are partly reversed, compared to what is observed at the individual level. This indicates that factors other than homeownership may be important at the neighborhood level. For instance, a strand of the literature (e.g., DiPAsquale and Glaeser, 1999) shows that the length of residence is more important than homeownership per se in affecting neighborhood satisfaction and community involvement. Our evidence complements this result, indicating that neighborhoods that are in majority composed of renters may be as good as those mainly made up of homeowners. In this respect, social factors are a crucial element. In fact, after controlling for the presence of the respondents within the same neighborhood for at least one year, a marginal increase in the share of renters (either private or social) living in the same neighborhood exerts a positive effect on the joint probability of being satisfied and attached to the neighborhood. As Table 5 shows, if the percentage of private renters increases, the joint probability to be satisfied and attached to the neighborhood also increases by $17.7 \%$, while the marginal effect is weaker for public renters (11.2\%). Also the expected marginal effect on the probability of being attached reflects the same pattern when comparing private to public renters $(18.6 \%$ vs $10.8 \%)$. Table 7 shows that accounting for individual unobservable effects does not substantially affect these estimates and their relative magnitudes.

To some extent, these results may be helpful to evaluate social housing policies designed to enhance individuals' responses to their neighborhoods. DiAZ-SERRAno (2006) indicates that in most of the EU-15 countries lower-income dwellers feel as satisfied with their neighborhoods as their higher income counterparts, suggesting that in these countries' governments (at the central, regional or local level) succeed in their social housing policies, since they are able to remove differentials between private and social rents. In the specific case of the UK, such an outcome is attained because the public sector is the most important supplier in the rental market. ${ }^{23}$ Our analysis adds to this study in at least two directions. First, we contemplate an important criterion, along with neighborhood satisfaction, represented by self-reported attachment: as discussed in Section 2, this measure allows us to account for individuals' affective evaluations of their neighborhoods, which may be as important as cognitive ones, for the reasons explained above. Second, from a policy viewpoint it appears that designing incentives that promote private over public renting may be welfare improving, in consideration of the higher multiplier effect on both attachment and satisfaction indicated by our estimates. 
In fact, such a distinctive feature may be explained by higher effectiveness of private landlords in selecting their tenants, as compared with the government, whose selection criteria are mainly income-based and often abstract from other evaluations on tenants' social characteristics and their potential matching with the rest of the neighborhood.

\section{Conclusions}

This paper explores personal and social determinants of individuals' responses to their neighborhoods. To this end, we identify a cognitive and an affective dimension along which individuals evaluate neighborhood quality. We then allow for various individual, social and contextual factors to affect the joint determination of individual neighborhood satisfaction (the cognitive component) and attachment to the neighborhood (the affective component).

We use an econometric framework that emphasizes the inter-dependence between individual preferences and the formation of social capital through different factors affecting attachment and neighborhood satisfaction. Moreover, we allow for unobservable correlated effects acting on individual preferences, which reflect the potential overlapping between satisfaction and attachment in individuals' perception of neighborhood quality. We rely on bi-variate probit techniques, using data from the British Household Panel Survey.

Three main results are produced. First, measures of satisfaction with the neighborhood and attachment are positively correlated, although each displays significant variation not explained by the other. Yet, accounting for the impact of endogenous, exogenous and contextual effects does not allow us to entirely capture such correlation. This evidence lends support to our initial conjecture, as it appears that neighborhood satisfaction and attachment may tap both cognitive and affective aspects of neighborhood quality. Concurrently, this result implies that exploring cognitive and affective individual responses in a separate fashion may entail a substantial bias due to the omission of relevant regressors.

Second, endogenous effects captured by the reference group average degrees of satisfaction and attachment are crucial determinants of individual preferences. In particular, the joint probability of being satisfied with and attached to the neighborhood increases substantially following a marginal increase in the average number of neighbors that prefer to stay (i.e., 
display attachment to the neighborhood). This reflects the implicit observation that higher residential turnover restricts the ability of individuals to develop informal ties and friendship networks with other residents in the neighborhood, thus depleting social capital.

Third, neighborhood contextual effects such as crime and vandalism, pollution and street noise display negative correlation with both dependent variables. In this respect, our estimates suggest that policies aimed at removing unfavorable contextual aspects and improve the quality of people's surroundings are likely to improve not only individuals' objective satisfaction, but also their sense of attachment, ultimately improving the overall evaluation of neighborhood quality.

Our analysis could be extended in a number of directions, which pertain to both econometric and policy-related aspects. We envisage three main avenues along which future research in this field could be conveniently deepened. First, as for many other social contexts, we could assume self-selection of individuals into neighborhoods, so that each individual actively decides where to live. Benabou $(1993,1996)$ and Durlauf $(1996)$ have put forward frameworks that link social interactions to neighborhood choice. This usually implies that the individual error terms will be correlated with neighborhood characteristics. To control for self-selection Durlauf and IOANNIDES (2010) suggest to treat group choice and behaviour within a group as a set of joint outcomes. In this respect one might argue that self-selection represents the outcome of an individual decision which depends on the social interactions that occur in all the neighborhoods over which each individual is choosing. To resolve econometrically the issue of self-selection the model necessitates the inclusions of the information on all the neighborhoods. This conditioning reflects the fact that the choice of a neighborhood depends on its characteristics as well as on those of the neighborhoods that were not chosen.

Second, in the present paper we have focused on the area of residence identified through postcodes. However, a different spatial range of analysis could be assumed. For instance, as stressed by Hidalgo and HeRnAndez (2001), attachment to and satisfaction with the neighborhood relate to different spatial scales. To complement this evidence, one could extend the analysis to see how attachment and satisfaction differ across households, areas of residence and cities. In fact, people can develop feelings of attachment towards places with a smaller spatial range, like a house or a street, while developing their sense of satisfaction with respect 
to places with a greater range, such as a city. This focus should help us at quantifying the importance of varying social and physical dimensions over which attachment and satisfaction develop and interact.

Finally, it should be acknowledged that, unlike attachment, satisfaction might not provide us with a clear idea of the level of commitment that people have at improving living conditions in the neighborhood (CONNERLY and MARANS, 1985). In fact, it is plausible to expect that people with higher attachment (induced, for instance, by the presence of a social network) should be more prone to upgrade their neighborhoods. In this respect public expenditure aimed at promoting neighborhood revitalization should not just consider the objective conditions of a certain area, but account for individuals' deep perceptions of their neighborhoods' quality. To this end future research needs to be focused on understanding to which extent attachment and satisfaction may proxy the level of commitment of incumbent residents at shaping the quality of their neighborhoods. In this respect, the availability of suitable survey and experimental data is of fundamental importance.

Acknowledgements. The authors wish to thank Roberta Distante, the editors and two anonymous reviewers for their helpful comments and suggestions. Any remaining errors are our own. Luisa Corrado acknowledges the support of the Marie-Curie IE Fellowship 039326 and the Marie Curie Excellence Award 2007. Emiliano Santoro gratefully acknowledges financial support from the UniCredit \& Universities Foscolo Foundation.

\section{Notes}

1. See, on these aspects, Connerly and Marans (1985), Ringel and Finkelstein (1991) and BELL et al. (2005).

2. In addressing these questions, it is important to acknowledge that the distinction between satisfaction and attachment reflects the standpoint of a vast literature exploring various aspects of subjective well-being (KAHNEMAN and DEATON, 2010).

3. Individuals can derive financial and/or emotional support from social networks. Under this perspective, changing neighborhood is likely to deplete the stock of social capital. 
4. See also Durlauf (2002).

5. In this respect, IYER et al. (2005) recognize the importance of pursuing a more regionspecific approach towards examining social capital development and impacts.

6. A comprehensive list and classification of the covariates is reported in Section 3.

7. MAnski (1993) considers three factors affecting individual choices (i) endogenous effects, intended as the propensity of an individual to conform to the average behavior in her peer group; (ii) exogenous effects, i.e. those effects exerted by the characteristics of the reference group; (iii) correlated effects, or the propensity of the individuals who belong to the same group to behave similarly because they have similar characteristics or just face and live in the same institutional and social environment.

8. As in Blume and Durlauf (2005) we assume agents' information set to include values of other determinants within their group, as well as the equilibrium expected choice in their group. Agents are assumed to be unable to observe the choice of others or their random payoff terms $\left(u_{k i g}, k=1,2\right)$.

9. Children in the original household are interviewed when they reach the age of 16 .

10. The BHPS aims at providing cross-sectional population estimates for the lifetime of the study in order to facilitate longitudinal research. The BHPS provides timely data on the short-term processes of change at the individual and household level for several domains (i.e. labour markets, income, savings and wealth, household and family organization, housing, consumption, health, social and political values, education and training). For further details, please refer to the Institute for Social and Economic Research Report, University of Essex (2006).

11. In turn, these contain, on average, 2,500 delivery points, which are approximately equivalent to addresses.

12. For the variable proxying individual neighborhood satisfaction (attachment) the fraction of missing values is around $4.7 \%(5.2 \%)$.

13. We do not include standard measures of socio-economic and occupational status. This choice is justified by the strong correlation of these variables with household income.

14. Social capital displays strong correlation with homeownership. Because of high transaction costs in the real estate market, homeowners tend to be relatively less mobile, and low 
levels of mobility predict high levels of social capital (GLAESER et al., 2002). Several works have emphasized that homeownership increases with social capital as homeowners usually invest more in long-term relationships with their neighbors (see, in particular, RoHE and Stewart, 1996; DiPasquale and Glaeser, 1999).

15. See Connerly and Marans (1985).

16. All correlation coefficients are between individual-level variables, with the exception of contextual effects such as crime, pollution, light, street and neighbors' noise, which are measured at the neighborhood level.

17. In the remainder we will use, with no distinction, the expressions "attachment" and "preference to stay", as the latter summarizes the variable used to proxy the former.

18. The selection of a discrete choice setting is also driven by a further consideration. As suggested by Blume and Durlauf (2005), whereas the reflection problem highlighted by MANSKI (1993) arises naturally in linear-in-means frameworks - producing lack of identification - it does not necessarily generalize to alternative data structures such as binary choice models. The logic of the reflection problem as it emerges in the linear model indicates why identification does not fail in binary choice models, as the dependent discrete variable that proxies our latent variables, bounded between zero and one, cannot be linearly dependent on contextual and exogenous factors. Non-linearity is crucial in this sense.

19. For more details on the implementation of bi-variate probit techniques, see WooldRIDGE (2002), Monfardini and Radice (2008). As to the application of these models to the analysis of social interactions, see JAENICKE (2009). Biprobit for STATA has been used to perform the estimation.

20. Note that we have reintroduced, without loss of generality, the time-subscript to account for the difference between individual fixed effects and other variables.

21. See, e.g., IoAnnides (2002), IoAnnides and Zabel (2003), Durlauf (2004).

22. Once quasi-fixed effects are considered, the endogeneity problem associated with this regressor is removed. Alternatively, a ceteris paribus analysis that does not account for quasifixed effects may not allow us to determine the causal effect exerted by the potentially endogenous variable (average satisfaction) on the dependent variables (individual satisfaction and attachment), the reason being that variations in the regressor reflect into variations in 
the error term, thus confounding the effect of the regressor on the dependent variables.

23. This is also the case in the Netherlands, Denmark and Ireland. Diaz-SERrano (2006) shows that analogous results can alternatively be obtained in two ways: (i) firstly, by giving an incentive to private homeowners to offer their flats in the rental market, which in turn implies a larger supply of dwellings for rent, and hence lower rents (this is the case of Germany); (ii) secondly, by providing housing allowances to low-income renters (this is the case of Belgium, France and Finland). 


\section{References}

[1] Becker G. S. and Murphy K. M. (2000) Social Economics: Market Behavior in a Social Environment. Harvard University Press, Cambridge MA.

[2] Bell P. A., Greene T. C., Fisher J. D. and Baum A. S. (2005) Environmental Psychology. Harcourt, New York.

[3] Benabou R. (1993) Workings of a city: location, education, and production, Quarterly Journal of Economics 108, 619-652.

[4] Benabou R. (1996) Equity and efficiency in human capital investment: the local connection, Review of Economic Studies 63, 237-264.

[5] Blume L. E. and Durlauf S. N. (2005) Identifying social interactions: a review, Working Paper No. 12, University of Wisconsin, Social Systems Research Institute, Madison.

[6] Brisson D. S. and Usher, C. L. (2005) Bonding social capital in low-income neighborhoods, Family Relations 54, 644-653.

[7] Brock W. and Durlauf S. N. (2001) Interactions-based models, in Heckman J. and LEAMER E. (Eds) Handbook of Econometrics, Vol. 5, pp. 3297-3380. North Holland Press, Amsterdam.

[8] Brock W. and Durlauf S. N. (2006) A multinomial choice model with social interactions, in Blume L. and Durlauf S. N. (Eds) The Economy as an Evolving Complex System III, pp. 175-206. Oxford University Press, New York.

[9] Chen S. and Zhou Y. (2007) Estimating a generalized correlation coefficient for a generalized bivariate probit model, Journal of Econometrics 41, 1100-1114.

[10] Connerly C. E. and R. W. Marans (1985) Comparing two global measures of perceived neighborhood quality, Social Indicators Research 17, 29-47.

[11] Diaz-Serrano L. (2006) Housing satisfaction, homeownership and housing mobility: a panel data analysis for twelve EU countries, IZA Discussion Papers No. 2318, IZA Bonn. 
[12] DiPasquale D. and Glaeser E. (1999) Incentives and social capital: do homeowners make better citizens?, Journal of Urban Economics 45, 354-84.

[13] Durlauf S. N. (1996) Neighborhood feedbacks, endogenous stratification, and income inequality, in Barnett W. A., Gandolfo G. and Hillinger C. (Eds) Dynamic Disequilibrium Modeling, pp. 505-534. Cambridge University Press, Cambridge UK.

[14] Durlauf S. N. (2002) On the empirics of social capital, Economic Journal 112, 459-479.

[15] Durlauf S. N. (2004) Neighborhood effects, in Henderson J. V. and Thisse J. E. (Eds) Handbook of Regional and Urban Economics, Vol. 4, pp. 2173-2242. North Holland Press, Amsterdam.

[16] Durlauf S. N. and Fafchamps M. (2005) Social capital, in Aghion P. and Durlauf S. N. (Eds) Handbook of Economic Growth, Vol. 1B, pp. 1639-1700. North-Holland Press, Amsterdam.

[17] Durlauf S. N. and Ioannides Y. M. (2010) Social interactions, Annual Reviews of Economics 2, 451-478.

[18] Elliott D. S., Wilson W. J., Huizinga D., Sampson R. J., Elliott A. and RANKIn B. (1996) The effects of neighborhood disadvantage on adolescent development, Journal of Research in Crime and Delinquency 33, 389-426.

[19] Fischer P. A. and Malmberg G. (2001) Settled people don't move: on life course and (im-)mobility in Sweden, International Journal of Population Geography 7, 357-371.

[20] Fishbein M. and Ajzen I. (1975) Belief, Attitude, Intention. and Behavior: An Introduction to Theory and Research. Addison-Wesley, Reading, MA.

[21] Ginther D., Haveman R. and Wolfe B. (2000) Neighborhood attributes as determinants of children's outcomes: how robust are the relationships?, Journal of Human Resources 35, 603-642.

[22] Glaeser E., Laisbon D. and Sacerdote B. (2002) The economic approach to social capital, The Economic Journal 112, 437-458. 
[23] Graham, B. S. (2008) Identifying social interactions through conditional variance restrictions, Econometrica, 76 (3), 643-660.

[24] Greene W. (2003) Econometric Analysis, Fifth Edition. Prentice Hall, New York.

[25] Harbison S. F. (1981) Family structure and family strategy in migration decision making, in De Jong G. F. and Gardner R. W. (Eds) Migration Decision Making: Multidisciplinary Approaches to Micro Level Studies in Developed and Developing Countries, pp. 225-251. Pergamon, New York.

[26] Hidalgo M. C. and Hernandez B. (2001) Place attachment: conceptual and empirical questions, Journal of Environmental Psychology 21, 273-281.

[27] Hsiao C. (2003) Analysis of Panel Data, Second Edition. Cambridge University Press, Cambridge UK.

[28] Hunter A. (1974) Symbolic Communities: The Persistence and Change of Chicago's Local Communities. The University of Chicago Press, Chicago.

[29] Ionnnides Y. M. (2002) Residential neighborhood effects, Regional Science and Urban Economics 32, 145-165.

[30] IoAnnides Y. M. and Zabel J. E. (2003) Neighbourhood effects and housing demand, Journal of Applied Econometrics 18, 563-584.

[31] Iyer S., Kitson M. and Toh B. (2005) Social capital, economic growth and regional development, Regional Studies 39, 1015-1040.

[32] KAN K. (2007) Residential mobility and social capital, Journal of Urban Economics 6 , $436-457$.

[33] Kahneman D. and Deaton A. (2010) High income improves evaluation of life but not emotional well-being, Proceedings of the National Academy of Sciences 107, 16489-16493.

[34] Kaplan S. and Kaplan R. (1982) Cognition and Environment: Functioning in an Uncertain World. Praeger, New York. 
[35] JAEniCKe J. (2009) Detecting social interactions in bi-variate probit models: some simulation results, REVSTAT-Statistical Journal 7, 67-85.

[36] Lee B. A., Oropesa R. S. and Kanan J. W. (1994) Neighborhood context and residential mobility, Demography 31, 249-270.

[37] Lichter D. T., McLaughlin D. K. and Cornwell G. T. (1995) Migration and the loss of human resources in rural America, in BeAulieu L. J. and Mulkey D. (Eds) Investing in People: The Human Capital Needs of Rural America, pp. 235-256. Westview Press, Boulder CO.

[38] Manski C. F. (1993) Identification of endogenous social effects: the reflection problem, Review of Economic Studies 60, 531-542.

[39] Manski C. F. (1995) Identification Problems in the Social Sciences. Harvard University Press, Cambridge MA.

[40] Mesch G. S. and Manor O. (1998) Social ties, environmental perception, and local attachment, Environment and Behavior 30, 504-519.

[41] Monfardini, C. and Radice R. (2008) Testing exogeneity in the bi-variate probit model: a Monte Carlo study, Oxford Bulletin of Economics and Statistics 70, 271-282.

[42] Mundlak Y. (1978) On the pooling of time series and cross section data, Econometrica 46, 69-85.

[43] O’Brien D., Phillips J. and Patsiorkovsky V. (2005) Linking indigenous bonding and bridging social capital, Regional Studies 39, 1041-1051.

[44] Ortalo-Magne F. and Rady S. (2008) Heterogeneity within communities: a stochastic model with tenure choice, Journal of Urban Economics 64, 1-17.

[45] Pickett K. E. and Pearl M. (2001) Multilevel analyses of neighborhood socioeconomic contexts and health outcomes: a critical review, Journal of Epidemiology and Community Health 55, 111-122. 
[46] Ringel N. B. and Finkelstein J. C. (1991) Differentiating neighborhood satisfaction and neighborhood attachment among urban residents, Basic and Applied Social Psychology 12, 177-193.

[47] Rohe W. M. and Stewart L. S. (1996) Homeownership and neighborhood stability, Housing Policy Debate 7, 37-81.

[48] Shumaker S. A. and Taylor R. B. (1983) Toward a clarification of people-place relationships: a model of attachment to place, in Fiemer N. R. and Geller E. S. (Eds) Environmental Psychology: Directions and Perspectives, pp. 219-251. Praeger, New York.

[49] Solon G., Page M. E. and Duncan G. J. (2000) Correlations between neighboring children in their subsequent educational attainment, Review of Economics and Statistics 82, 383-392.

[50] Speare A. Jr., Kobrin F. and Kingkade W. (1982) The influence of socioeconomic bonds and satisfaction on interstate migration, Social Forces 61, 551-574.

[51] VARADY D. (1983) Determinants of residential mobility decisions. The role of government services in relation to other factors, Journal of American Planning Association 49, 184199.

[52] Western J., Stimson R., Baum S. and Van Gellecum Y. (2005) Measuring community strength and social capital, Regional Studies 39, 1095-1109.

[53] Wooldridge J. M. (2002) Econometric Analysis of Cross Section and Panel Data. MIT Press, Cambridge MA. 


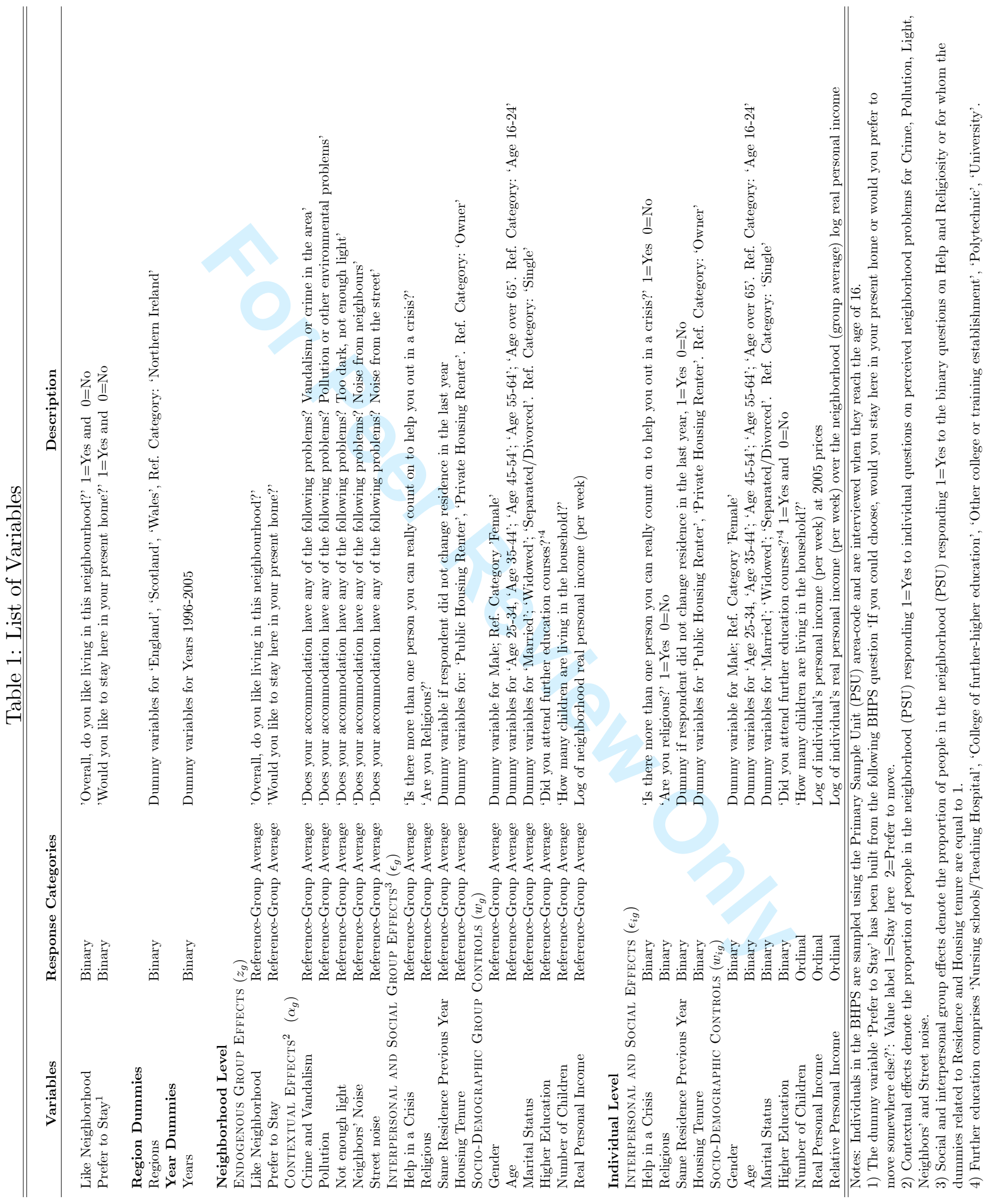


Table 2: Summary Statistics

\begin{tabular}{lcccc}
\hline \hline \multicolumn{1}{c}{ Variable } & Means (\% if counts) & Std. Dev. & Min & Max \\
\hline Like Neighborhood & & & & 1 \\
Prefer To Stay & 0.911 & 0.284 & 0 & 1 \\
Crime and Vandalism & 0.685 & 0.464 & 0 & 1 \\
Pollution & 0.184 & 0.387 & 0 & 1 \\
Not enough Light & 0.078 & 0.268 & 0 & 1 \\
Street Noise & 0.064 & 0.245 & 0 & 1 \\
Neighbors' Noise & 0.164 & 0.370 & 0 & 1 \\
Help in a Crisis & 0.108 & 0.310 & 0 & 1 \\
Religious & 0.210 & 0.407 & 0 & 1 \\
Same Residence Previous Year & 0.628 & 0.483 & 0 & 1 \\
Homeowner & 0.858 & 0.349 & 0 & 1 \\
Private Housing Renter & 0.730 & 0.443 & 0 & 1 \\
Public Housing Renter & 0.081 & 0.273 & 0 & 1 \\
Age 16-24 & 0.187 & 0.390 & 0 & 1 \\
Age 25-34 & 0.118 & 0.323 & 0 & 1 \\
Age 35-44 & 0.162 & 0.368 & 0 & 1 \\
Age 45-54 & 0.184 & 0.387 & 0 & 1 \\
Age 55-64 & 0.150 & 0.357 & 0 & 1 \\
Age over 65 & 0.123 & 0.329 & 0 & 1 \\
Male & 0.196 & 0.397 & 0 & 1 \\
Single & 0.456 & 0.498 & 0 & 1 \\
Married & 0.263 & 0.440 & 0 & 1 \\
Separated/Divorced & 0.550 & 0.498 & 0 & 9 \\
Widowed & 0.106 & 0.307 & 0 & 1 \\
Number of Children & 0.082 & 0.274 & 0 & 13.957 \\
Higher Education & 0.538 & 0.950 & 0 & 0 \\
Real Personal Income & 0.381 & 0.486 & 0 & 1 \\
\hline \hline
\end{tabular}

Notes: The statistics refer to variables measured at the individual level. The variable 'Real Personal Income' is the log of the average weekly real personal income. The summary statistics are defined over a number of 128313 observations which is the total number of observations, net of missing values. 
Table 3: Pairwise Correlations Between the Dependent Variables and Each Covariate

\begin{tabular}{lrr}
\hline \hline & Like Neighborhood & Prefer To Stay \\
Like Neighborhood & 1.00 & 0.30 \\
Prefer To Stay & 0.30 & 1.00 \\
Crime and Vandalism & -0.21 & -0.17 \\
Pollution & -0.09 & -0.11 \\
Not enough Light & -0.09 & -0.10 \\
Street Noise & -0.15 & -0.18 \\
Neighbors' Noise & -0.19 & -0.20 \\
Help in a Crisis & 0.02 & 0.02 \\
Religious & 0.03 & 0.09 \\
Same Residence Previous Year & 0.01 & 0.01 \\
Homeowner & 0.12 & 0.10 \\
Private Housing Renter & -0.01 & -0.07 \\
Public Housing Renter & -0.13 & -0.07 \\
Age & 0.05 & 0.19 \\
Male & 0.02 & -0.01 \\
Married & 0.04 & 0.06 \\
Single & -0.04 & -0.10 \\
Separated/Divorced & -0.03 & -0.05 \\
Widowed & 0.02 & 0.11 \\
Number of Children & -0.03 & -0.06 \\
Higher Education & 0.03 & -0.03 \\
Real Personal Income & 0.04 & 0.01 \\
\hline
\end{tabular}
contextual effects for crime, pollution, light, street and neighbors' noise, which are measured at the neighborhood level. 
Table 4: Model Estimates

Bi-variate Probit

Like Neighborhood Prefer To Stay

Coefficient S.E. Coefficient S.E.
Like Neighborhood Prefer To Stay Coefficient S.E. Coefficient S.E.

Neighborhood Level

Endogenous Group Effects $\left(z_{g}\right)$

Like Neighborhood $3.411^{* * *}$

Prefer To Stay

(0.219) $-0.827 * * *$

$0.204)$

$3.529^{* * *}$

(0.224) $-0.834^{* * *}$

$(0.204)$

Contextual Effects $\left(\alpha_{g}\right)$

Crime and Vandalism

$-0.446^{* * *}$

(0.139) $2.889 * * *$

$(0.122)$

$0.275^{*}$

(0.142) $2.892^{* * * *}$

$(0.122)$

Pollution

$\begin{array}{llll}-0.074 * * * & (0.022) & -0.140 * * * & (0.019)\end{array}$

$-0.455^{* * *}$

$\begin{array}{lll}(0.015) & -0.308^{* * *} \quad(0.013)\end{array}$

Not enough Light

$-0.209 * * * \quad(0.022) \quad-0.255^{* * *} \quad(0.020)$

Street Noise

$\begin{array}{llll}-0.242^{* * *} & (0.016) & -0.273^{* * *} & (0.014)\end{array}$

$-0.071^{* * *}$

$-0.210^{* * *}$

$(0.022)-0.140 * * *$

$(0.022) \quad-0.254^{* * *}$

$-0.236^{* * *}$

(0.016) $-0.273^{* * *}$

(0.019)

Neighbors' Noise

$-0.457 * * *$

$(0.017)-0.494^{* * *}$

NTERPERSonal and Social group EFfects $\left(\epsilon_{g}\right)$

Help in a

$\begin{array}{lll}-0.392 & (0.346) & 0.578^{*}\end{array}$

Religious

$-0.032$

Same Residence Previous Year - 0.043

Private Housing Renter

$\begin{array}{lll}0.043 & (0.328) & 0.245\end{array}$

$(0.016)$

$-0.459^{* * *}$

$(0.017)-0.490 * * *$

(0.300) $\quad-0.478$

$0.079)-0.200^{* * *} \quad(0.070)$

$-0.478$

$(0.289) \quad-0.024$

Public Housing Renter $0.250 * * * \quad(0.093) \quad 0.313 * * * \quad(0.081)$

-0.024
0.099

$0.232^{* *}$

(0.352) $\quad 0.593^{* *}$

Socio-Demographic Group Controls $\left(w_{g}\right)$

Age 25-34

$\begin{array}{llll}0.446 & (0.283) & 0.711^{* * *} & (0.239)\end{array}$

Age 35-44

0.086

0.069

$(0.293) \quad 0.502^{* *}$

$(0.239)$
$(0.249)$

0.455

Age 45-54

Age 55-64

Age over 65

$(0.304)$

0.091

0.081

0.053

(0.213)

Male

Married

$\begin{array}{lll}0.007 & (0.255) & 0.126\end{array}$

$\begin{array}{lll}-0.353^{*} & (0.207) & -0.060\end{array}$

$-0.060$

$(0.213)$
$(0.176)$

0.032

$-0.367^{*}$

$(0.143)$

$-0.109$

$\begin{array}{lll}0.175 & (0.232) & 0.209\end{array}$

Widowed

$\begin{array}{lll}-0.165 & (0.292) & -0.334\end{array}$

(0.208)

$(0.252)$

0.105

$-0.255$

Number of Children

Higher Education

0.020

Real Personal Income

$0.179 *$

$(0.066) \quad 0.012$

$(0.096) \quad 0.130$

$(0.059)$

$(0.084)$

0.023

0.003

$0.189^{* * *}$

(0.080) $-0.201^{* * *}$

$0.332) \quad 0.224$

$\begin{array}{lll}(0.173) & 0.545^{* * *} & (0.149) \\ (0.095) & 0.310^{* * *} & (0.081)\end{array}$

Individual Level

Interpersonal And Social Effects $\left(\epsilon_{i g}\right)$

Help in a Crisis $0.067^{* * *}$

Religious $0.059 * * *$

Same Residence Previous Year

$0.050 * * *$

Private Housing Renter

$-0.068 * * *$

Public Housing Renter $-0.255^{* * *}$

Socio-Demographic Controls $\left(w_{i g}\right)$

Age 25-34

$\left.w_{i g}\right)$

Age 35-44

$0.038^{*}$

$-0.024$

Age 45-54

Age 55-64

Age over 65

Male

Married

Separated/Divorced

Widowed

Number of Children

Higher Education

Relative Personal Income

0.039

$0.161^{* * *}$

$0.041^{* *}$

0.021

$-0.040$

$0.107^{* * *}$

$-0.016^{*}$

$0.045^{* * *}$

$0.021^{* * *}$

$\begin{array}{lll}(0.020) & 0.070^{* * *} \quad(0.015)\end{array}$

$\begin{array}{lll}(0.017) & 0.083^{* * *} \quad(0.015)\end{array}$

$0.069^{* * *}$

$\begin{array}{lll}(0.288) & 0.721^{* * *} \quad(0.240)\end{array}$

$(0.297) \quad 0.503 * *-(0.250)$

$\begin{array}{lll}(0.369) & 0.338 & (0.304)\end{array}$

$\begin{array}{lll}(0.331) & 0.239 & (0.284)\end{array}$

$\begin{array}{lll}(0.256) & 0.134 & (0.214)\end{array}$

$\begin{array}{lll}(0.213) & -0.059 & (0.176)\end{array}$

$\begin{array}{lll}(0.165) & -0.203 \quad(0.143)\end{array}$

$\begin{array}{lll}(0.236) & 0.211 \quad(0.208)\end{array}$

$\begin{array}{lll}(0.294) & -0.336 \quad(0.253)\end{array}$

$\begin{array}{lll}(0.067) & 0.014 & (0.059)\end{array}$

$\begin{array}{lll}(0.098) & 0.124 & (0.084)\end{array}$

$\begin{array}{lll}(0.067) & 0.013 \quad(0.058)\end{array}$

Region Dummies

England

$(0.014) \quad 0.013$

$(0.025) \quad-0.201 * * * \quad(0.021)$

$0.058 * * *$

$0.049 * * *$

$-0.069 * * *$

$0.071^{* * *}$

$(0.015)$

$(0.020)-0.128 * * *$

(0.019)

$-0.261^{* * *}$

$(0.014) \quad 0.012$

$\begin{array}{llll}(0.020) & -0.129 * * * & (0.017) & 0.015\end{array}$

$(0.023) \quad 0.001$

(0.024) $0.115 * * *$

$(0.018)$

$0.027) \quad 0.196^{* * *}$

(0.020)

0.032

$0.030)$

$(0.025)$

(0.016) -0.016

$0.022) \quad 0.043^{* *}-(0.018)$

$\begin{array}{lll}(0.028) & -0.082^{* * *} \quad(0.024)\end{array}$

$\begin{array}{lll}(0.041) & 0.313^{* * *} \quad(0.035)\end{array}$

$\begin{array}{lll}(0.009) & -0.001 \quad(0.008)\end{array}$

$\begin{array}{lll}(0.009) & -0.001 & (0.008) \\ (0.017) & -0.053^{* * *} & (0.015)\end{array}$

$-0.027$

0.029

$0.142 * * * \quad(0.030) \quad 0.435 * * * \quad(0.025)$

$\begin{array}{llll}0.040^{* *} & (0.017) & -0.015 & (0.014)\end{array}$

$\begin{array}{llll}0.024 & (0.022) & 0.043^{* *} & (0.018)\end{array}$

$\begin{array}{llll}-0.040 & (0.028) & -0.081^{* * *} \quad(0.024)\end{array}$

$\begin{array}{llll}0.094^{* *} & (0.042) & 0.308^{* * *} & (0.035)\end{array}$

$\begin{array}{llll}-0.021^{* *} & (0.009) & -0.001 & (0.008)\end{array}$

$0.045 * * \quad(0.018) \quad-0.052 * * * \quad(0.015)$

$0.019 * * * \quad(0.006) \quad-0.015$ *** $\quad(0.005)$

Wales

$0.190 * * * \quad(0.053) \quad-0.024 \quad(0.045)$

$(0.045)$

Scotland

Constant

$0.187 * * * \quad(0.054) \quad-0.024$

$0.217 * * * \quad(0.052) \quad-0.033$

$(0.045)$

$0.180^{* * *}$

$-0.023$

$0.206 * * *$

$-3.394^{* * *}$

$\begin{array}{lll}(0.052) & -0.031 & (0.044)\end{array}$

Year Dummies 1996-2005

$(0.651)-1.236^{* *} \quad(0.567)$

$0.662)-1.233^{* *}$

$(0.569)$

$\chi^{2}(1)$

$\operatorname{Pr} o b>\chi^{2}$

Log-Likelihood

Wald $\chi^{2}$

Degrees of freedom

$\operatorname{Pr} o b>\chi^{2}$

Observations

0.514

3370

0

$-101659$

9691

106

128313

23258
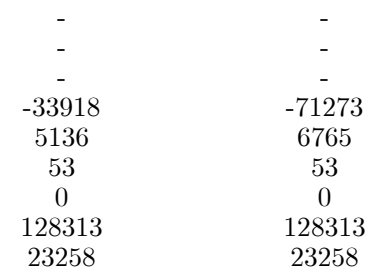

Significance Level at *** $1 \%, * * 5 \%, * 10 \%$

Notes: Standard errors in parentheses. Robust clustered errors for repeated observations by individuals. 
Table 5: Average Marginal Effects

Neighborhood Level

Endogenous Group EfFects $\left(z_{g}\right)$

Like Neighborhood

Prefer to stay

$-0.086$

Contextual Effects $\left(\alpha_{q}\right)$

Crime and Vandalism

Pollution

Not enough light

Street noise

Neighbors' Noise

$0.938^{* * *}$

$-0.128 * * *$

$-0.049 * * *$

$-0.096^{* * *}$

$-0.103^{* * *}$

$-0.193^{* * *}$

Interpersonal and Social Group Effects $\left(\epsilon_{g}\right)$

Help in a Crisis

Religious

0.164

$-0.065 * * *$

Same Residence Previous Year $\quad 0.075$

Private Housing Renter

$0.177^{* * *}$

$0.112^{* * *}$

TROLS $\left(w_{g}\right)$

Age 25-34

Age 35-44

Age 45-54

Age 55-64

Age over 65

Male

Married

Separated/Divorced

$0.164^{*}$

0.106

0.071

0.040

$-0.037$

$-0.067$

0.075

Widowed

Number of Children

Higher Education

Real Personal Income

$-0.114$

0.004

0.042

0.013

Individual Level

Interpersonal and Social Effects $\left(\epsilon_{i g}\right)$

Help in a Crisis $\quad 0.025^{* * *}$

Religious

$0.029 * * *$

Same Residence Previous Year

Private Housing Renter

$0.006^{*}$

$-0.070^{* * *}$

Public Housing Renter

$-0.056^{* * *}$

Socio-Demographic Controls $\left(w_{i g}\right)$

Age 25-34

Age 35-44

Age 45-54

Age 55-64

Age over 65

Male

Married

Separated/Divorced

Widowed

Number of Children

Higher Education

Relative Personal Income

Region Dummies

England

Wales

Scotland

$-0.041^{* * *}$

0.002

$0.034^{* * *}$

$0.061 * * *$

$0.136^{* * *}$

$-0.003$

$0.014^{* *}$

$-0.028 * * *$

$0.097^{* * *}$

$-0.001$

$-0.014^{* * *}$

$-0.004^{* *}$

0.002

$-0.001$

$-0.005$

0.68

Year Dummies 1996-2005

Joint Probability

\begin{abstract}
$0.535^{* * *}$
$-0.892^{* * *}$

$0.056^{* * *}$

$0.039^{* * *}$

$0.064^{* * *}$

$0.068^{* * *}$

$0.116^{* * *}$
\end{abstract}

$-0.215^{* *}$

$0.061^{* * *}$

$-0.078$

$-0.162^{* * *}$

$-0.079^{* * *}$

$-0.190^{* * *}$

$-0.152^{* *}$

$-0.096$

$-0.067$

$-0.039$

$-0.009$

0.059

$-0.052$

0.092

$-0.002$

$-0.039$

0.010
$-0.199^{* * *}$
$0.060^{* * *}$
$0.017^{* * *}$
0.001
$0.004^{* * *}$
$0.005^{* * *}$
$0.009^{* * *}$

$0.035^{* *}$

$-0.004$

0.007

0.008

$-0.004$

$-0.003$

0.009

0.005

0.004

0.003

$0.016^{*}$

$-0.002$

$-0.003$

$-0.001$

$-0.001$

0.002

$-0.009^{* * *}$

\section{$-0.249 * * *$ \\ $-0.106 * * *$ \\ $0.056 * * *$ \\ $0.010 * * *$ \\ $0.028 * * *$ \\ $0.031^{* * *}$ \\ $0.068 * * *$}

0.015

0.008

$-0.005$

$-0.024$

$-0.028^{* * *}$

$-0.055^{* *}$

$-0.020$

$-0.014$

$-0.008$

$-0.004$

0.029

0.010

$-0.019$

0.022

$-0.002$

$-0.005$

$-0.015^{* *}$
$0.449^{* * *}$
$0.045^{* *}$
$-0.072^{* * * *}$
$-0.010^{* * *}$
$-0.031^{* * *}$
$-0.036^{* * *}$
$-0.078^{* * *}$

$-0.051$

$-0.004$

$-0.002$

0.015

$0.033^{* * *}$

0.059

0.011

0.009

0.003

0.001

$-0.046^{*}$

$-0.008$

0.022

$-0.021$

0.003

0.003

$0.024^{* * *}$
$-0.285^{* * *}$ $0.998 * * *$

$-0.113^{* * *}$

$-0.049^{* * *}$

$-0.093^{* * *}$

$-0.099 * * *$

$-0.184 * * *$

$0.199^{*}$

$-0.069^{* * *}$

0.083

$0.186^{* * *}$

$0.108^{* * *}$

$0.246 * * *$

$0.173^{* *}$

0.111

0.075

0.043

$-0.020$

$-0.070$

0.072

$-0.115$

0.003

0.044

0.004

$-0.016^{* * *}$

$-0.021^{* * *}$

$-0.003$

$0.061^{* * *}$

$0.018^{* * *}$

$0.044^{* * *}$

0.002

$-0.037^{* * *}$

$-0.057 * * *$

$-0.116^{* * *}$

$0.008^{* *}$

$-0.011^{* *}$

$0.023^{* * *}$

$-0.084^{* * *}$ 
Bi-variate Probit \begin{tabular}{lll}
\hline Like Neighborhood & Prefer To Stay \\
\hline Coefficient & S.E. & Coefficient S.E.
\end{tabular} \begin{tabular}{lll}
\hline Like Neighborhood & Prefer To Stay \\
\hline Coefficient & S.E. & Coefficient
\end{tabular}

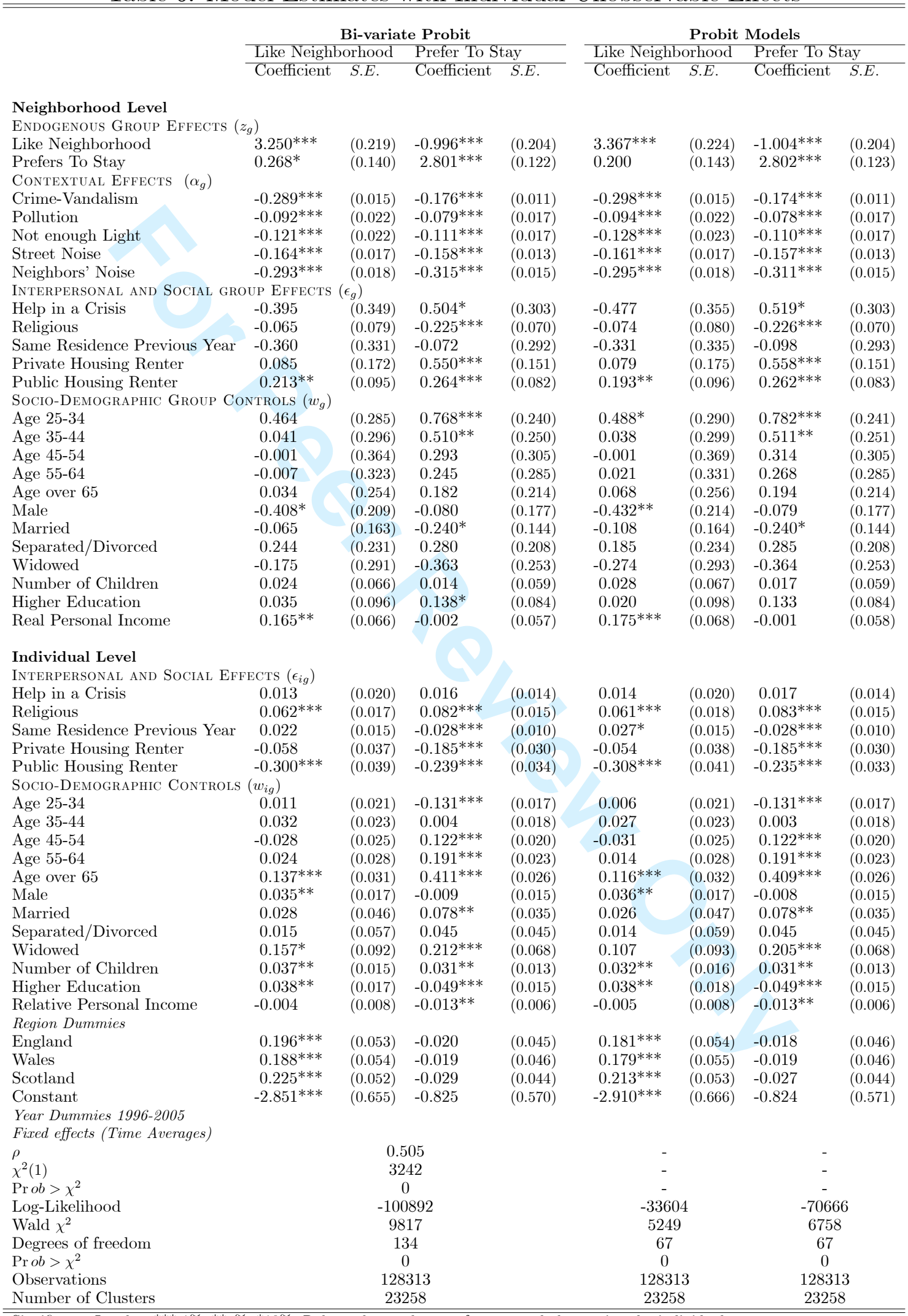

Significance Level at $* * * 1 \%, * * 5 \%, * 10 \%$. Robust clustered errors for repeated observations by individuals. 
Table 7: Average Marginal Effects with Individual Unobservable Effects

Neighborhood Level

Endogenous Group Effects $\left(z_{g}\right)$

Like Neighbor

Prefer to stay

$-0.148^{* *}$

Contextual Effects $\left(\alpha_{g}\right)$

Crime and Vandalism

Pollution

Not enough light

Street noise

Neighbors' Noise

Interpersonal and Social group EfFects $\left(\epsilon_{g}\right)$

$\begin{array}{lc}\text { Help in a Crisis } & 0.140 \\ \text { Religious } & -0.075^{*}\end{array}$

$-0.075^{* * *}$

Same Residence Previous Year

Private Housing Renter

Public Housing Renter

$0.180^{* * *}$

$0.095^{* * *}$

Socio-Demographic Group Controls $\left(w_{g}\right)$

Age 25-34

Age 35-44

Age 45-54

Age 55-64

Age over 65

Male

Married

Separated/Divorced

$0.269^{* * *}$

$0.164^{* *}$

0.093

0.078

0.060

$-0.047$

$-0.080$

0.102

Widowed

Number of Children

Higher Education

Real Personal Income

$-0.125$

0.006

0.046

0.008

Individual Level

Interpersonal and Social Effects $\left(\epsilon_{i g}\right)$

Help in a Crisis $\quad 0.006$

Religious

$0.029 * * *$

Same Residence Previous Year

Private Housing Renter

Public Housing Renter

$-0.008^{* *}$

$-0.064^{* * *}$ $-0.095^{* * *}$

Socio-Demographic Controls $\left(w_{i g}\right)$

Age 25-34

Age 35-44

Age 45-54

Age 55-64

Age over 65

Male

Married

Separated/Divorced

Widowed

Number of Children

Higher Education

Relative Personal Income

Region Dummies

England

Wales

Scotland

$-0.042 * * *$

0.003

$0.036^{* * *}$

$0.059^{* * *}$

$0.128^{* * *}$

$-0.001$

$0.026^{* *}$

0.015

$0.072^{* * *}$

$0.012^{* * *}$

$-0.014^{* * *}$

$-0.004^{* *}$

0.004

0.002

0.001

0.68

Fixed effects (Time Averages)

Joint Probability

Marginal Probability

$-0.004$

$-0.021^{* * *}$

$0.011^{* * *}$

$0.057^{* * *}$

$0.050 * * *$

$0.044^{* * *}$

0.001

$-0.040^{* * *}$

$-0.056^{* * *}$

$-0.111^{* * *}$

0.006

$-0.023^{* *}$

$-0.013$

$-0.054^{* * *}$

$-0.007^{*}$

$0.019^{* * *}$

$0.004^{* *}$

0.022

0.020

$0.026^{*}$

0.25

$-0.196^{* * *}$
$0.061^{* * *}$
$0.011^{* * *}$
$0.003^{* *}$
$0.003^{* * *}$
$0.004^{* * *}$
$0.007^{* * *}$

$0.034^{* *}$

$-0.003$

0.017

0.010

$-0.004$

$-0.003$

0.012

0.008

0.007

0.003

0.019 *

$-0.003$

$-0.005$

$-0.001$

$-0.001$

0.002

$-0.009^{* * *}$

0.001

$-0.001^{* * *}$

$-0.002^{* *}$

$-0.002$

$0.010^{* * *}$

$-0.004^{* * *}$

$-0.002$

$0.005^{* *}$

$0.004^{* *}$

$0.003^{*}$

$-0.002^{* *}$

0.001

0.001

$-0.003$

$-0.001$

$-0.003^{* * *}$

0.001

$-0.011^{* * *}$

$-0.009 * * *$

$-0.011^{* * *}$

0.02
$-0.227^{* * *}$
$-0.096^{* * *}$
$0.032^{* * *}$
$0.010^{* * *}$
$0.014^{* * *}$
$0.019^{* * *}$

$0.039^{* * *}$

0.017

0.011

0.030

$-0.021$

$-0.024^{* * *}$

$-0.057^{* *}$

$-0.017$

$-0.008$

$-0.006$

$-0.008$

$0.034^{*}$

0.012

$-0.027$

0.023

$-0.002$

$-0.006$

$-0.013^{* *}$

$$
-0.001
$$

$-0.007^{* * *}$

$-0.001$

$0.010^{* * *}$

$0.035^{* * *}$

0.003

$-0.003$

$-0.001$

$-0.007^{* * *}$

$-0.020^{* * *}$

$-0.002^{*}$

$-0.004$

$-0.002$

$-0.016^{* * *}$

$-0.004^{* * *}$

$-0.002$

0.001

$-0.015 * * *$

$-0.013^{* * *}$

$-0.016^{* * *}$

0.05 